\title{
LA ORDEN DE ALCÁNTARA Y EL PAPADO DURANTE LA EDAD MEDIA SEGÚN LA DOCUMENTACION PONTIFICIA

\author{
(Primera Parte)
}

POR

\author{
Luis Corral VaL
}

Universidad Complutense, Madrid

\section{RESUMEN}

El autor de este artículo ofrece los primeros resultados de su investigación sobre los fondos medievales referidos a la orden de Alcántara que se conservan, principalmente, en los Archivos Vaticanos, en la Real Academia de la Historia y en la Biblioteca Nacional de Madrid. En esta primera entrega expone, asimismo, sus conclusiones históricas, a la luz de la documentación pontificia, acerca de los orígenes de la orden y las relaciones de la misma con la jurisdicción papal.

\section{Abstract}

The Order of Alcántara and the Papacy during middle ages according to the pontifical documentation

The author offers his first researches about the medieval holdings of the order of Alcantara that are mainly located in the Vatican Archives, in the Spanish Academy of History and in the National Library in Madrid. In this first part he also exposes his historical conclusions about the origins of the order and its relationship with the papal jurisdiction. 
La principal dificultad para estudiar cualquier aspecto de la historia de la orden de San Julián del Pereiro, desde 1218 llamada orđen de Alcántara ${ }^{1}$, es la pérdida de su archivo a comienzos del siglo XIX. Por tanto, no conservamos las bulas originales - salvo rarísimas excepciones - dirigidas por la Sede Apostólica a los alcantarinos. Sin embargo, algunos documentos pontificios de dicha orden fueron publicados en dos colecciones antes de perderse dicho archivo. La primera de ellas recoge los privilegios papales concedidos al maestre y freires del Pereiro-Alcántara compilados por Juan Calderón de Robles en el siglo $\mathrm{XVII}^{2}$. La recopilación calderoniana contiene numerosos fallos. Hemos detectado errores de transcripción y, sobre todo, incontables equivocaciones en la datación crónica de las bulas. Por consiguiente, es la fuente menos indicada para fijar una cronología fiable de los documentos pontificios.

La segunda colección es el Bulario de la orden de Alcántara publicado en el siglo XVIII ${ }^{3}$. Reúne todo tipo de documentación referida a los sanjulianistas o alcantarinos: documentos reales, pontificios, episcopales, particulares, etc. Es una edición más cuidada que la de Calderón de Robles -especialmente en la datación de las bulas-, aunque no está exenta de errores y omisiones en la transcripción.

Otras obras publicadas, aunque no nos transmiten íntegramente el texto pontificio, sí mencionan documentación papal de esta orden, a veces con cierto detalle. Hay que destacar, sobre todo, la crónica de Alonso de Torres y Tapia ${ }^{4}$. Este autor, prior alcantarino en el siglo XVII, cita cuantiosas bulas en su obra, algunas de ellas ausentes de las colecciones de Calderón de Robles y del Bulario. Su aportación es muy valiosa, porque trabajó sobre los documentos originales conservados en su época en el archivo de la orden. De menor importancia para nuestro propósito es la crónica de Rades y Andrada ${ }^{5}$. Este cronista compuso su obra a partir de traslados del archivo de San Benito de Alcántara. Parece ser que los freiles de Alcántara no quisieron facilitar el trabajo a Rades,

I En dicho afio los calatravos cedieron Alcántara, junto con todas sus posesiones en el reino de León, a la orden de S. Julián del Pereiro y reconocieron al maestre sanjulianista el derecho a estar presente en la elección del maestre de Calatrava. A cambio, a este último, se le otorgó el derecho de visita y corrección de los freires del Pereiro.

2 J. CAlderón DE RoBles, Privilegia selectiora Militiae Sancti Iuliani de Pereiro (hodie de Alcantara) Cisterciensis Ordinis, a Summis Pontificibus hactenus concessa, Madrid 1627.

3 I. J. de ORTEGa Y COTES; J. FERNÁNDEZ DE BRIZUEl LA; P. de ORTEGA ZúNIIGA Y ARANDA, Bullarium Ordinis Militiae de Alcantara, olim S. Juliani del Pereiro, Madrid 1759.

4 A. de TORRES Y TAPIA, Crónica de la Orden de Alcántara, Madrid 1763, 2 vols. La obra fue publicada en dicho año, pero el autor la escribió en tiempos de Felipe III.

5 F. de RADES Y ANDRADA, Chronica de las tres Ordenes y Cavallerias de Santiago, Calatrava y Alcantara: en la qual se trata de su origen y successo, y notables hechos en armas de los maestres $y$ Cavalleros de ellas; y de muchos señores de tífulo y otros Nobles que descienden de los maestres: y de muchos otros Linages de España, Toledo 1572. 
porque era freile calatravo. Tuvo que contentarse con unas pocas copias de documentos del archivo, las crónicas nacionales y particulares y algunas referencias de los documentos de Calatrava y Uclés. Mucho menos relevantes para recopilar documentación pontificia sobre los alcantarinos son las obras de Zapater ${ }^{6}$, cronista del Císter que cita algunos documentos de los archivos de la orden, y Caro de Torres?

Ś́lo conocemos un trabajo moderno que recopila algunas bulas alcantarinas: es el realizado por Trenchs Odena ${ }^{8}$. Pero ninguno de los documentos regestados es inédito. La novedad que ofrece este artículo es dar la signatura correcta $^{9}$ de las bulas y presentar éstas agrupadas por Órđenes Militares. Inserta trece bulas del papa Benedicto XII a la orden de Alcántara.

Otras colecciones documentales $\mathrm{u}$ obras históricas recogen algunos documentos pontificios alcantarinos sueltos o menciones a ellos. Entre ellas podemos destacar los trabajos de la Escuela Francesa en Roma ${ }^{10}$, los bularios de los franciscanos ${ }^{11}$, capuchinos ${ }^{12}$, carmelitas ${ }^{13}$, dominicos ${ }^{14}$, calatravos ${ }^{15}$, santiaguistas $^{16}$, algunos bularios portugueses ${ }^{17}$, el cartulario de los hospitalarios ${ }^{18}, y$

- M. R. ZAPATER Y LÓPEZ, Císter militante en la campaña de la Iglesia contra la sarracena furia. Historia general de las ilustrísimas, ínclitas y nobilísimas cavallerias del Templo de Salomón, Calatrava, Alcántara, Avis, Montesa y Christo, Zaragoza 1662.

7 F. CARO DE TORRES, Historia de las Órdenes Militares de Santiago, Calatrava y Alcántara desde su fundación hasta el Rey Felipe Segundo, Administrador perpetuo dellas, Madrid 1629.

8 J. TRENCHS ODENA, "Benedicto XII y las Órdenes Militares hispanas: regesta de los textos papales", Anuario de Estudios Medievales, XI (1981), 139-150.

$\checkmark$ Sin embargo, hemos detectado algunas erratas, posiblemente de imprenta, al citar las signaturas del Archivo Vaticano y las referencias a las colecciones de la Escuela Francesa en Roma.

${ }^{10} \mathrm{~L}$. Auvra\}, Les registres de Grégoire IX, Paris 1896-1955, 4 vols. P. GaSNAULT; M. H. LAURENT; N. GOTTERI, Innocent VI. Lettres secrètes ef curiales, Paris 1959-76, 2 vols. P. LECACHEUX; G. MOLLAT, Urbain V. Lettres secrètes et curiales se rapportant d la France, Paris 1902 55. G. MOLLAT, Jean XXII (1316-34). Lettres communes, Paris 1904-47. G. MOLLAT, Grégoire XI. Lettres secrètes et curiales intéressant les pays autres que la France, Paris 1962-65. J. M. VIDAL, Benoît XII (1334-42). Lettres communes et curiales, Paris 1902-11, 3 vols. J. M. VIDAL; G. MoLLAT, Benoit XII (I334-42). Lettres closes et patentes intéressant les pays autres que la France, Paris 1913-50, 2 vols.

II Bullarium Franciscanum, nova series: IV-1 (1484-89); IV-2 (1489-92), Grottaferrata 1989-90.

${ }_{12}$ Bullarium Ordinis FF. Minorum S. P. Francisci Capucinorum, Roma 1740-52.

${ }^{13}$ Bullarium Carmelifanum, Roma 1715-68.

14 Bullarium O.FF. Praedicatorum, Roma 1729-40.

15 I. J. DE ORTEGa Y COTES; J. F. Álvarez DE Baquedano; P. de ORTEGa ZúNínga Y ARANDA, Bullarium ordinis militiae de Calatrava, Madrid 1761.

16 A. F. AGUADO DE Córdoba; A. A. AlemÁN Y Rosales; J. López BURGaleta, Bullarium equestris ordinis S. Lacobi de Spatha, Madrid 1719.

17 A. J. da CosTA; M. A. F. MARQues, Bulário Portuguess. Inocêncio III (1198-1216), Coimbra 1989. A. D. de SOUSA COSTA, Monumenta Portugaliae Vaticana, Braga-Porto 1970, 3 vols.

18 J. DEL AVILLe DE Roulx, Cartulaire générale de l'Ordre des Hospitaliers de Saint Jean de Jérusalem, 1100-1310, París 1894-1906, 4 vols. 
las obras de Fernández Catón ${ }^{19}$, Goñi Gaztambide ${ }^{20}$, Pressuti21, Arias de Quintanadueñas ${ }^{22}$, Migne ${ }^{23}$, Nieto Soria ${ }^{24}$, Suárez Femández ${ }^{25}$, Raynaldi ${ }^{26}$, Jaffé $^{27}$, Potthast ${ }^{28}$, Mansilla ${ }^{29}$, Milian Boix ${ }^{30}$, Rius Serra ${ }^{31}$, Rodríguez de La$\mathrm{ma}^{32}$, Zunzunegui ${ }^{33}, \mathrm{O}^{\prime}$ Callaghan ${ }^{34}$, Peñafiel y Araújo ${ }^{35}$, Muñoz Gallardo ${ }^{36}, \mathrm{y}$ Muñoz de San Pedro ${ }^{37}$.

Si nos referimos a los estudios históricos sobre las relaciones entre los papas y la orden de Alcántara en la época medieval, podemos afirmar que no existen precedentes historiográficos sobre el tema. No conocemos ningún trabajo de investigación que haya estudiado directamente este asunto. Sólo es posible espigar algunos datos -fragmentarios y aislados- de las crónicas de

${ }^{19}$ J. M. FERNÁNDEZ CATÓN, “Índice-regesta de los documentos pontificios hasta Martín V pertenecientes al archivo del real convento de San Marcos de León de la orden de Santiago", Archivos leoneses, 13 (1959), 353-96.

20 J. GoÑı GAZTAMBide, "Los españoles en el Concilio de Constanza", Hispania Sacra, XVI (1962), 253-386; XVIII (1965), 103-58, 265-332.

21 P. PREsSUTti, Regesta Honorii Papae III, Roma 1888 (I), Roma 1895 (II).

22 J. ARIAS DE QUINTANADUEÑAS, Antigüedades y santos de la muy noble villa de Alcántara, Madrid 1661, 3 libros.

23 J. P. MIGNE, Patrologiae cursus completus, series latina, Paris 1844-75, vol. 215.

${ }^{4}$ J. M. NIETO SORIA, Iglesia y génesis del Estado Moderno en Castilla (1369-1480), Madrid 1994.

${ }^{25}$ L. SUÁREZ FERNÁNDEZ, Castilla, el Cisma y la crisis conciliar (1378-90), Madrid 1960.

26 O. RAYNALDI, Annales Ecclesiastici ab anno 1198 ubi desinit card. Baronius, Lucae 1747-56.

27 P. JAFFÉ, Regesta Pontificum Romanorum ab condita ecclesia ad annum post Christum Natum MCXCVIII, Lipsiae 1888, Graz 1956, 2 vols.

${ }^{28}$ A. POTTHAST, Regesta Pontificum Romanorum inde ab anno 1198 ad annum 1304, Berlin $1874-75,2$ vols.

${ }^{29}$ D. MANSILLA, "Fondos españoles de archivos romanos", Anthologica Annua, II (1954), 393455; III (1955), 555-617. IDEM, La documentación pontificia hasta Inocencio III (965-1216), Roma 1955. IDEM, La documentación española del Archivo del Castel S. Angelo (395-1498), Roma 1959. IDEM, La documentación pontificia de Honorio III (1216-27), Roma 1965.

30 M. MLLIAN BOIX, El fondo "Instrumenta Miscellanea" del Archivo Vaticano, Documentos referentes a España (853-1782), Roma 1969.

31 J. RIUS SERRA, Regesto iberico de Calixto III, Madrid 1945, 2 vols.

32 I. RODRÍGUEZ DE LAMA, La documentación pontificia de Alejandro $N$ (1254-61), Roma 1976.

33 J. ZUNZUNEGUI ARAMBURU, Bulas y cartas secretas de Inocencio VI (1352-62), Roma 1970.

34 J. F. O'CALlaGHAN, "The Foundation of the Order of Alcántara (1176-1218)", Catholic Historical Review, XLII (1962), 471-86.

35 A. de PENAFIEL Y ARAÚJO, Obligaciones y excelencias de las tres Órdenes Militares de Santiago, Calatrava y Alcántara, Madrid 1643.

${ }_{36}$ J. A. MUÑOZ GALLARDO, " Fue la Orden de Alcántara filial de la de Calatrava ?", Revista de Estudios Extremeños, XXI (1965), 247-303.

37 M. MUN̄OZ DE SAN PEDRO, Don Gutierre de Sotomayor, Maestre de Alcántara, Cáceres 1949.

Medievalia Hispanica

Hispania Sacra 49 (1997) 
Torres y Tapia, y Rades y Andrada, de la obra de Chamorro Pérez ${ }^{38}$, $O^{\prime}$ Callaghan ${ }^{39}$, Goñi Gaztambide ${ }^{40}$, Ladero Quesada ${ }^{41}$ y de una conferencia de B. Palacios Martín ${ }^{42}$.

Esta situación hizo imprescindible un detenido trabajo de investigación, principalmente sobre los fondos del Archivo Secreto Vaticano ${ }^{43}$ y sobre las numerosas bulas alcantarinas conservadas en la Biblioteca Nacional de Madrid y en Ia Real Academia de la Historia. Una vez reunida toda esta documentación pontificia, junto a la ya encontrada en las obras impresas, fue posible esbozar un primer estudio histórico de carácter general acerca de la orden de Alcántara y el Pontificado en la época medieval.

\section{LOS FONDOS ALCANTARINOS DEL ARCHIVO SECRETO VATICANO Y DE OTROS ARCHIVOS.}

Los registros de bulas pontificias conservados en el Archivo Secreto Vaticano, especialmente los Registros Vaticanos, han sido considerados como la mejor fuente para la historia europea de los siglos XIII y XIV ${ }^{44}$. Son un rico arsenal de documentación para el estudio de las Órdenes Militares durante la Edad Media, especialmente para la orden de Alcántara, ya que no conservamos las bulas originales de su archivo central.

Los registros de bulas son los volúmenes que recogen la transcripción de las partes esenciales de algunos documentos pontificios que la Curia Romana conservaba junto a sít ${ }^{45}$. Eran copias autorizadas de los documentos emanados

\footnotetext{
${ }^{38}$ F. ChAMORRo PÉREZ, La Orden Militar de Alcántara. Estudio histórico-jurfdico, Madrid 1968 (tesis doctoral inédita)

39 J. F. O'CALLAGHAN, "The Foundation of the order of Alcantara (1176-1218), Catholic Historical Review, XLII (1962), 471-86

40 J. GOÑ GAZTAMBIDE, "Los españoles en el Concilio de Constanza", Hispania Sacra, XVI (1962), 253-386; XVIII (1965), 103-158 y 265-332.

"1 M. F. LADERO QUESADA, "La incorporación del maestrazgo de Alcántara a la Corona", Hispania, XLII (1982), 5-14.

42 B. PAlacios MaRTín, "La orden de Alcántara y su incorporación a la corona", Conferencia en el salón de actos de la Torre de los Lujanes, Madrid 7 marzo 1996.

${ }^{43}$ Agradecemos al Consejo Superior de Investigaciones Cientificas la concesión de una beca anual en la Escuela Española de Historia y Arqueología en Roma que nos ha permitido estudiar las ricas series de registros del Archivo Vaticano durante 1995.

${ }_{44}$ K. A. FINK, Das Vatikanische Archiv, Roma 1951, p. 35. Afirmación corroborada por el que fue destacado prefecto del Archivo Vaticano: M. GIUSTI, Studi sui Registri di bolle papali, Città del Vaticano 1968, p. X.

45 P. RABIKAUSKAS, Diplomatica generalis (praelectionum lineamenta), Romae 1989, pp. 67-68.
} 
de la Sede Apostólica ${ }^{46}$. Fueron realizadas, al menos a partir del siglo XIII, por una categoría especial de funcionarios dentro de la Cancillería Pontificia: los registradores. La operación de registro no constituía un asunto de poca importancia. Era cuidada de forma especial, incluso por encima de la operación de sellado, al menos según las constituciones cancillerescas de finales del siglo $\mathrm{XIII}^{47}$. Conservamos muy pocos registros anteriores al siglo XIII, aunque es generalmente admitida la existencia de los mismos ya desde el siglo IV ${ }^{48}$. La serie continua de registros conservados comienza con el pontificado de Inocencio III (1198-1216). Las razones para registrar un documento fueron variadas y no las conocemos bien. A veces era el mismo peticionario quien lo solicitaba, por si el original se perdía y era necesario volver a expedirlo. En otras ocasiones era la curia la que precisaba llevar un control de los documentos expedidos, ya que tras la muerte del pontífice anterior los destinatarios solicitaban la confirmación de los privilegios concedidos por el papa difunto. El registro de las cartas pontificias ("modus registrandi") era realizado de forma abreviada: eran omitidas la "intitulatio" y la "salutatio"; la "inscriptio" o "directio" y las fórmulas estereotipadas del texto quedaban abreviadas; si la "datatio" coincidía con la del documento anterior el registrador lo indicaba con la fórmula "datum ut supra"; si el mismo texto era enviado a distintos destinatarios, aquél era copiado en el registro una sola vez, acompañado de la indicación "in eundem modum", "simili modo" etc., especificando el destinatario.

Según Rabikauskas ${ }^{49}$, durante los primeros dos tercios del siglo XIII sólo una pequeña parte de las letras pontificias fueron transcritas en los libros de registro ${ }^{50}$. La razón de la selección parece que no fue siempre ni unívoca ni clara. Sólo una parte de la documentación pontificia que hemos recopilado ha sido encontrada en los registros del Archivo Vaticano. Sin embargo, hay que tener en cuenta que muchos volúmenes de registros fueron perdidos, especialmente con motivo de la caótica vuelta a Roma desde París de la documentación vaticana incautada por Napoleón.

\footnotetext{
46 Según Thomas Frenz, no está definitivamente aclarado si la operación de registro era realizada a partir de las minutas o de los originales. Normalmente, los registros de la Cámara y los secretos debían ser realizados a partir de la minuta y los registros de las "litterae communes" a partir del original. Sin embargo, en este tema no hay coincidencia entre los diplomatistas pontificios. Vid. T. FRENZ, I Documenti Pontifici nel Medioevo e nell'Età Moderna, Città del Vaticano 1989, p. 56.

47 G. DIGARD; M. FAUCON; A. THOMAS; R. FAWTIER, Les registres de Boniface VIII (12941303), Paris 1884-1939, t. IV, p. XCVII. 103.

48 L. E. BOYLE, A survey of the Vatican Archives and of its medieval holdings, Toronto 1972, $\mathrm{p}$.

49 P. RABIKAUSKAS, Diplomatica pontificia (praelectionum lineamenta), Romae 1994, p. 74.

so Otros autores, por ejemplo Domínguez Sánchez, llegan a dar una cifra: parece que durante el siglo XIII sólo se registraron el diez o el veinte por ciento de los diplomas expedidos, vid. S. DOMíNGUEZ SÁNCHEZ, Documentos de Clemente N (1265-68) referentes a España, León 1996, p. 69.
}

Medievalia Hispanica

Hispania Sacra 49 (1997) 
Los registros pontificios eran coleccionados en libros o volúmenes ("registronum ordo") siguiendo el orden de los años de pontificado"si. Sin embargo, el "iter" burocrático podía ser causa de retrasos en la consignación de las letras apostólicas en los libros de registro, lo cual tenía inevitables consecuencias $^{52}$.

Durante el período aviñonés fue costumbre hacer una copia de los registros de cartas pontificias de papel ("registra chartacea") en pergamino ("registra pergamenea"). Cuando un documento era copiado en el volumen de pergamino ("Registra Vaticana"53), los registradores procedían a consignarlo en el registro en papel ("Registra Avenionensia"54). Por esto al final de los libros-registro en papel de cartas pontificias aparece la nota "scriptum est in pergameno". Por tanto, durante esta época, los Reg. Aven. formaron los registros originales donde se copiaban directamente las minutas $\mathrm{u}$ originales de los documentos que debían ser expedidos. Los Reg. Vat., en cambio, fueron transcripciones autorizadas de los Reg. Aven. -y no directamente de las minutas o de los originales- que se llevaban a cabo en la misma Cancillería ${ }^{55}$.

Desde finales del pontificado de Juan XXII (1316-34) ${ }^{56}$ los registros comenzaron a estructurarse según la materia de la que tratasen. Esta tendencia

si Generalmente la fecha deterninante para datar correctamente los años de pontificado en los documentos papales era ci día de la coronación, posterior al de la eleccion; vid. G. GUALDO, Sussidi per la consultazione dell'Archivio Vaticano, Città del Vaticano 1989, p. 380. Los autores del "Bullarium" de la orden de Alcántara siguen, en cambio, la fecha de la elección para la datación de los documentos.

52 T. FRENZ, Op. cir, p. 55.

${ }^{53}$ Los Registros Vaticanos, llamados así por el lugar donde se conservan desde hace siglos, forman la más antigua e importante serie de registros de epístolas de papas medievales. La colección conserva 2042 volúmenes: desde el pontificado de Juan VIII (872-82) hasta 1605, sin embargo, la serie ininterrumpida comienza con el pontificado de Inocencio III (1198).

54 Los Registros Avifronenses, trasladados desde Aviñón en 1783, comprenden hoy 353 volúmenes, algunos de ellos en mal estado de conservación. Abarcan los pontificados de los papas y antipapas aviffonenses (1316-1423). Para consultar esta serie nos resultó muy útil la utilización de dos colecciones de la Sala de Índices del Archivo Vaticano. La primera realizada por P. de Montroy entre 1718 y 1732, siguiendo el orden alfabético, dí6cesis por diócesis, de cada volumen de la serie (índices 557-641). La segunda colección, índices 642-669, fue obra de J. Martin desde 1711; procede volumen. por volumen y registro a registro. Los índices de Martin son una guía completa de los fondos de los Reg. Aven., mientras que los de Montroy son útiles, pero no exhaustivos.

ss Por ello, cuando una letra pontificia ha sido conservada tanto en los Reg. Vat. como en los Reg. Aven., como ha ocurrido en algunos documentos recopilados de la orden de Alcántara, se debe dar primacía a la segunda serie de registros. Las copias de los Reg. Vat. no son despreciables, pues se realizaban bajo la atenta mirada de un corrector, sin embargo contienen algunos errores, especialmente en la transcripción de nombres de lugar o persona.

56 Juan XXII fue canciller del rey francés de Sicilia y con su liegada al Papado emprendió profundas reformas, muchas de ellas con el sello de la Cancillería de los Anjou; vid. R. von HECKEL, 
fue reforzándose durante el siglo XIV, y así quedaron estereotipados algunos modelos ${ }^{57}$. Además, con este mismo pontífice apareció una nueva serie de registros llamados secretos. Éstos contenían los documentos "de curia" redactados en la Cámara Secreta del papa. Igualmente, desde mediados del siglo XIV, la Cámara Apostólica tuvo su propio registro donde recopilaron sus documentos. Tanto los registros secretos como los camerales pertenecen hoy a la serie de los "Registra Vaticana".

Cuando en 1377 Gregorio XI retornó a Roma, la Cancillería posiblemente permaneció en Aviñón: parece ser que el papa sólo fue acompañado por un pequeño grupo cancilleresco bajo la dirección de un "regens cancellariam". En el momento de producirse el cisma, probablemente Clemente VII mantuvo casi íntegra la Cancillería y Urbano VI tuvo que reconstruirla completamente. Sin embargo, no hay unanimidad entre los estudiosos ${ }^{58}$. Tras el fin del Cisma de Occidente, los registros pasaron a consignarse sobre papel y desaparecio completamente la utilización del pergamino como soporte material. Con Bonifacio IX (1389-1404) comenzó una nueva serie de registros de Cancillería: los "Registra Lateranensia"59. Éstos son, en cierto sentido, como una continuación no inmediata de los Reg. Aven., aunque las epístolas papales son agrupadas bajo diversas denominaciones en cada volumen (beneficios, dispensas, indulgencias, etc.) y los registros llevan normalmente dos datas (de concesión de la gracia y de expedición).

\footnotetext{
"Das päpstliche und sicilische Registerwesen in vergleichender Darstellung mit besonderer Berilcksichtigung der Urspringe", Archiv für Urkundenforschung, 1 (1908), 371-510.

57 Por ejemplo: "de litteris dominorum cardinalium", "de dignitatibus / canonicatibus / prebendis / beneficiis vacantibus / vacaturis", "de diversis formis", "de conservatoriis", "de altari portatili", "de plentaria remissione", "de litteris dimissorum", etc.

58 Ottenthal y Pasztor opinan que la Cancillería de Gregorio XI pas6 a Urbano VI y fue Clemente VII quien debió formarla de nuevo. Frenz y Serra Estellés mantienen que Urbano VI tuvo que crear "ex novo" una Cancillería, porque la antigua había permanecido en Aviñón. Vid. E. von OTTENTHAL (ed,), Regulae Cancelleriae Apostolicae. Die päpstlichen Kanzleiregeln von Johannes XXII bis Nicolaus V, Aalen 1968, p. XI. E. PÁszTOR, "La Curia Romana all"inizio dello scisma d'Occidente" en Genèse et débuts du Grand Schisme d'Occident, Avignon 25-28 septembre 1978, Paris 1980 (- Colloques internationaux du Centre National de la Recherche Scientifique, $n^{\circ}$. 586), p. 40. T. FRENZ, Op. cit., p. 56. J. SERRA ESTELLÉS, Los Registros de Súplicas y Letras pontificias de Clemente VII de Aviñón (1378-94). Estudio diplomático, Rorna 1988, p. 26, nota 3.

${ }^{59}$ Como en las dos series anteriores estamos ante una denominación convencional o signatura genérica, no archivística. Estos registros nacieron cuando los papas habían dejado el palacio de Letrán como residencia desde hacía mucho tiempo. Tomaron este nombre porque, hacia finales del siglo pasado, fueron trasladados al Archivo Secreto Vaticano desde el palacio de Letrán, donde se encontraban tras su vuelta desde París en 1817. Hoy la serie suma 2467 volúmenes, más algunos números repetidos. Comienzan en 1389 y terminan en 1897 . Como los Reg. Aven. provienen de la Cancillería Apostólica, no de diversos departamentos de expedición, como es el caso de los Reg. Vat.
} 
Hay otras series de registros ${ }^{60}$ que también nos han suministrado documentación de la orden de Alcántara. Es el caso de los "Registra Supplicationum"61 y de los "Armaria" XXXI, XXXII y XXXIX. También hemos localizado un par de cartas pontificias referidas a los alcantarinos en un fondo con documentos muy antiguos: el "Archivum Arcis" (A.A.) ${ }^{62}$, así denominado por la conservación de estos fondos durante un tiempo en el Archivo del Castel de Sant'Angelo.

La Biblioteca Nacional de Madrid y la Real Academia de la Historia conservan también muchos documentos pontificios referidos a la orden de Alcántara. En la Sala de Manuscritos de la Biblioteca Nacional existen tres manuscritos con bulas alcantarinas ${ }^{63}$. En la colección de don Luis de Salazar y Castro, conservada en la Real Academia de la Historia, quedan copias manuscritas de numerosas bulas concedidas a los alcantarinos. Fueron recopiladas a finales del siglo XVII y comienzos del XVIII. El Archivo Histórico Nacional sólo conserva unos pocos documentos referidos a la orden que debieron extraviarse antes de la destrucción del archivo de San Benito de Alcántara. Contiene algunas referencias a bulas pontificias. Asimismo existen algunas copias de documentos pontificios en el Archivo Capitular de Coria, en el Archivo de la Embajada Española ante la Santa Sede, en el Archivo General de Simancas y en la Biblioteca Apostólica Vaticana.

Toda esta documentación medieval ${ }^{64}$ recopilada nos ha permitido hacer un primer estudio histórico, aún muy general y en la perspectiva de la documenta-

60 Nuestro trabajo sobre los registros de bulas nos ha permitido constatar lo injusto de la siguiente afirmacion: "Los registros pontificios tienen gran interés hístórico, pero no diplomático". Los documentos originales son el mejor medio para conocer la actividad y composición de la Cancillería, pero la ayuda que en este punto proporciona el análisis de los registros no puede ser minusvalorada. La reconstrucción del "iter documentorum", la forma y momento de registrar, y otros muchos aspectos de la Cancillería y de los miembros que en ella trabajaban, vienen aclarados en algunos aspectos por las numerosas notas marginales y otras acotaciones y signos que aparecen en los registros.

61 Contienen la transcripción de las súplicas de "gratia" y de "iustitia" dirigidas al romano ponlífice. La serie conservada comienza con Clemente VI en 1342 y llega hasta 1899: está constituida por 7363 volúmenes y cuenta con una buena guía publicada por B. KATTERBACH, Inventario dei Registri delle Suppliche, Citta del Vaticano 1932.

62 Es una sección dividida en "armaria superiora et inferiora". La inmensa mayoría de la documentación de este fondo proviene de lo que fue mandado a la Santa Sede por personas, organismos, instituciones etc. No es, pues, un fondo que recopile los registros de las cartas apostólicas emitidas por los papas.

63 Mss. 621, 622 y 13.014. El ms. 13.014, del siglo XVIII, tiene mucho menos interés. En cambio los ms. 621 y 622 contienen cuantiosos Iraslados realizados por fray Bemardo de Fresneda, obispo de Cuenca, y su secretario, durante los años 1562-63.

64 En el Archivo Secreto Vaticano fueron utilizados los índices, inventarios, catálogos, sumarios y diversos instrumentos de localización antiguos y modemos de la rica Sala de f́ndices de dicho 
ción pontificia, sobre los orígenes de la orden de Alcántara, sus relaciones con las jurisdicciones papal y diocesana, su dependencia del Císter, y la relación con otras Órdenes Militares y con la Monarquía durante la época medieval. Dicha época termina para nosotros en 1494, cuando renunció a su dignidad el último maestre de los alcantarinos y el papa nombró a los Reyes Católicos administradores del maestrazgo.

\section{LOS ORÍGENES DE LA ORDEN DE SAN JULIÁN DEL PEREIRo SEGÚN LA DOCUMENTACIÓN PAPAL.}

El tema de los orígenes temporales de la cofradía del Pereiro es un problema complejo y muy difícil de esclarecer, debido a los escasos documentos conservados. Los dos cronistas principales de la orden, Francisco de Rades y Andrada (calatravo del siglo XVI) y Alonso de Torres y Tapia (prior alcantarino en el siglo XVII) discrepan acerca de los comienzos de esta institución. Rades y Andrada declara desconocer el año de aparición de los sanjulianistas y cita a Gómez como primer fundador de dicha milicia ${ }^{65}$. Torres y Tapia ${ }^{66}$, siguiendo a fray Bernardo de Brito, apunta bastantes datos sobre los orígenes de la cofradía: en el año 1156 un tal Suero de Salamanca, acompañado por varios seguidores, fue a Extremadura a combatir a los moros en las fronteras del reino de León. Allí encontraron a un ermitaño llamado Amando, quien había acompañado al conde Enrique de Portugal a Tierra Santa, y que vivía en aquel momento en la iglesia del Pereiro, a orillas del río Coa. Al saber el eremita que estos caballeros querían construir una fortaleza para combatir a los musulmanes, les indicó un lugar adecuado cerca de su iglesia. También les aconsejó que pidieran una regla de vida a Ordoño, obispo de Salamanca. Dicho obispo, miembro del Císter, les concedió los estatutos de la orden y nombró a Suero cabeza de este nuevo grupo o cofradía religioso-militar, que pasó a denominar-

archivo. Son muy variados en cuanto a calidad y legibilidad. Los antiguos suman casi 700 volúmenes, compuestos la mayor parte durante los tres primeros siglos de vida del archivo y clasificados juntos como serie en 1901. Los modemos empezaron a ser elaborados desde dicho año. Una vez agotados dichos instrumentos, emprendimos la búsqueda directa y pormenorizada de documentos relacionados con la orden de Alcántara hasta 1503 en las dos series más antiguas de registros de bulas: los "Registra Vaticana" y los "Registra Avenionensia". Fueron recopilados, juntos con los fondos de la Biblioteca Nacional, la Real Academia de la Historia, el Archivo Histórico Nacional, otros archivos y la documentación de las colecciones publicadas, alrededor de 250 documentos pontificios referidos a los sanjulianistas o alcantarinos en la Edad Media. Serán publicados próximamente dentro de la Colección Diplomática medieval de la orden de Alcántara, que ahora está en curso de elaboración bajo Ia dirección del Dr. B. Palacios Martín de la Universidad Complutense.

65 F. de RADES Y ANDRADA, Op. cit., ff. 1r-2r.

66 A. de TORRES Y TAPIA, Op. cit., I, ff. 5-8.

Medievalia Hispanica

Hispania Sacra 49 (1997) 
se orden de San Julián del Pereiro. Tras la muerte de Suero en combate contra los islamitas, le sucedió su hermano Gómez.

El primero que publicó esta historia de Suero y sus primeros compañeros fue fray Bernardo de Brito ${ }^{67}$, historiador cisterciense nacido en 1569 en una población muy próxima al Pereiro, lugar que visitó en 1588. Según Pinto de Azevedo ${ }^{68}$, estas circunstancias permitieron a B. de Brito conocer la tradición oral sobre los comienzos de la orden, fuente de la versión del historiador cisterciense. Pinto de Azevedo reconoce que B. de Brito no es fiable al aducir documentos, ya que se han detectado falsedades en su crónica del Císter: una regla de la orden de Avis supuestamente realizada por el abad cisterciense de S. Jôao de Tarouca, un fantástico relato de la institución en 1168 de la orden de St. Michael, etc ${ }^{69}$.

Por tanto, podríamos llegar a la conclusión de que los datos presentados por fray Bernardo de Brito son inventados. Sin embargo, poseemos otra fuente que nos transmite noticias muy similares y que, según Azevedo, es independiente de B. de Brito: Antonio de Yepes publicó en 1621 una crónica de la orden de $S$. Benito en la que se ocupó, con bastante brevedad, de los orígenes de San Julián del Pereiro. En esta obra dicho autor afirma que sus aseveraciones están basadas en Rades, Bernardo de Brito y especialmente en "unos papeles del Doutor Roco de Campo Frío, inquisidor que fue de Cordova y de Valladolid y aora del supremo Consejo, del hábito de Alcántara, bien conocido... por su mucha erudición ${ }^{70 \%}$.

En 1642 Ángel Manrique en sus Anales ${ }^{71}$ se ocupó de los orígenes de nuestra orden. Reveló por primera vez la existencia de un documento en latín, sin datar ni firmar, sobre los comienzos de la milicia del Pereiro. Declaró que era una copia autentificada por dos notarios de un documento inserto en la segunda parte de un códice del monasterio de Alcobaça. Manrique sostuvo que éste fue el escrito que vio B. de Brito para componer su versión sobre el inicio de la cofradía del Pereiro. En los códices de Alcobaça, hoy en la Biblioteca Nacional de Lisboa y en el Archivo de la Torre do Tombo, no hay rastro de

67 B. de BRITo, Chrónica de Cister, Lisboa 1602, pp. 29496.

68 R. PINTo DE AzeVEDO, “A Ordem Militar de S. Juliâo do Pereiro, depois chamada de Alcântara", Anuario de Estudios Medievales, XI (1981), p. 717.

69 En 1834 Antonio de Almeida compiló una lista de errores y falsificaciones en la crónica del Císter de fray Bemardo de Brito: "Erros historicos-chronologicos de Fr. Bernardo de Brito na Chronica de Cister correctos em 1834", Memorias da Academia Real das Sciencias de Lisboa, XII, parte I (1837), pp. 45-152.

70 A. de YEPES, Coronica General de la Orden de San Benito, Valladolid 1621, t. VII, c. 1. Roco de Campofrío (1565-1638) fue también obispo de Zamora, Badajoz y Coria y escribió una "Historia de la orden de Alcántara".

7 A. MANRIQUE, Annales Cistercienses, Lyon 1642-49, t. II, f. 280. 
este documento de Manrique. Lo podemos considerar, por tanto, como un documento espurio. Fue compuesto, probablemente, en el siglo XVII y siguió como modelo las referencias dadas por Bernardo de Brito en su crónica del Císter de 1602 y algunos datos de la crónica de Yepes de 1621.

Pinto de Azevedo $^{72}$ concluye su investigación señalando que B. de Brito y Roco de Campo Frío nos transmiten, aunque algunos datos podrían ponerse en duda, la tradición oral viva en la zona del Pereiro que ellos reciben. Según Azevedo, podemos admitir que antes de $1176^{73}$ dicha orden o cofradía existía bajo la jefatura de un tal Suero de Salamanca y se había establecido en las orillas del río Coa para luchar contra los almohades, aunque su fuerza y efectivos eran aún bastante humildes. Está documentado, según Azevedo, que el obispo Ordoño de Salamanca ocuṕ́ esta sede desde el año 1159 al 1164. Por tanto, en algún momento durante estos cinco años, los caballeros encabezados por Suero fueron a solicitarle una regla de vida para su cofradía.

Otro investigador de temas śanjulianistas, $O^{\prime}$ Callaghan, niega verosimilitud a la versión de B. de Brito ${ }^{74}$, al que considera un historiador poco fiable y muy distante en el tiempo. Sin embargo, O'Callaghan parece desconocer la versión de Roco de Campo Frío, conocida a través de Yepes, que apoya los datos transmitidos por Bernardo de Brito. Pero hace referencia, aunque de forma fugaz y sin resaltar su importancia - al igual que Lomax ${ }^{75}$-, a una bula de Inocencio III del año 1207. Esta bula, no mencionada por Pinto de Azevedo, creemos que podría esclarecer nuestro tema, por lo que incluimos su texto completo:

Innocentius episcopus, servus servorum Dei. Dilectis filis magistro et fratribus de Pirario, salutem et apostolicam benedictionem. Solet annuere Sedes Apostolica piis votis et honestis petentium precibus favorem benevolum impertiri. Eapropter, dilecti in Domino filii, vestris iustis postulationibus grato concurrentes assensu, decimas, ecclesias et possesiones, quas per quadraginta annos et amplius quiete et pacifice possedistis, auctoritate vobis apostolica confirmamus: inhibentes districtius, ne quis vos super his indebite molestare presumat. Nulli ergo omnino hominum liceat hanc paginam nostre inhibitionis infringere vel ei ausu temerario contraire. Si quis autem hoc attentare presumpserit, indignationem omnipotentis Dei et beatorum Petri et Pauli apostolorum eius,

72 R. PINTO DE AZEVEDO, Op. cit., pp. 726-27.

${ }^{73} \mathrm{El}$ primer documento que conservamos sobre la orden es de enero de 1176, cuando Femando II de León donó El Pereiro y Raigadas a Gómez y los hermanos de S. Julián.

${ }^{74}$ J. F. O'CALLAGHAN, "The Foundation of the Order of Alcántara (1176-1218)", Catholic Historical Review, XLII (1962), pp. 475-76.

${ }^{75}$ D. W. LomaX, "Las milicias cistercienses en el reino de León", Hispania, XXIII (1963), p. 31. Fecha incorrectamente la bula en 1206.

Medievalia Hispanica

Hispania Sacra 49 (1997) 
se noverit incursurum. Datis Lateranensi, secundo idus (kalendas) aprilis, pontificatus nostri anno decimo 76 .

El papa confirma a la orden los diezmos, iglesias y posesiones que por más de cuarenta años había poseído pacíficamente y sin discusión ${ }^{77}$. Parece deducirse -aunque es una entre otras posibles hipótesis- que la hermandad del Pereiro ya existía antes de 1167. Así, apoyándonos en esta bula, podríamos situar el origen temporal de la pequeña cofradía de S. Julián del Pereiro aproximadamente durante el tercer cuarto del siglo XII, muy cercano a las fechas de nacimiento de otras Órdenes Militares castellano-leonesas como Santiago y Calatrava. Sin embargo, debemos ser muy prudentes: quizá el papa fue informado de la antigüedad de las posesiones del Pereiro por los mismos sanjulianistas o sus procuradores en Roma, que alegaban en su petición la pacífica posesión durante más de cuarenta años.

Hay que ser mucho más desconfiados -principalmente por su lejanía en el tiempo- al referimos a los detalles ofrecidos por Bernardo de Brito y Roco de Campo Frío, inverificables según el estado actual de nuestros conocimientos. Apelar, como hace Azevedo, a una tradición oral que supuestamente recibieron estos autores muchos siglos después, es demasiado arriesgado: $1^{\circ}$ ) porque ninguno de los dos autores, B. de Brito y R. de Campo Frío, afirman que se basen en una tradición oral; $2^{\circ}$ ) aun suponiendo que existiera realmente esa tradición oral en la zona del Pereiro, no podemos probar que estuviera libre de deforma-

${ }^{76}$ B) B.N., ms. 622, f. 60; C) R.A.H., Col. Sal., I-19, ff. 192-192v; I-40, f. 48v; D) A.H.N., 00 . MM., Registro Escrituras Calatrava, t. II, 1342c, f. 30; E) A.H.N., OO. MM., Registro Escrituras Calatrava, t. III, 1343c, f. 61. No podemos precisar exactamente el dia y mes de la bula, pues unos autores leen "kalendas" y otros "idus". Con respecto a las citas de Ja bulas en este artículo debemos aclarar lo siguiente: para no recargar en exceso las notas a pie de página sólo citamos la copia más fiable (por ejemplo, todos los registros conservados en el Archivo Vaticano), a no ser que no se pueda determinar cuál es, en ese caso citamos todas las copias. Algunas de estas bulas están publicadas, regestadas o citadas en diversas obras. Dejamos para el momento en que se publique la Colección Diplomática medieval de la orden de Alcántara las referencias pormenorizadas en el aparato erudito de todas estas obras. Las abreviaturas utilizadas en este artículo han sido las siguientes: A.C.C. $=$ Archivo Capitular de Coria; A.H.N. = Archivo Histórico Nacional; A.E.E.S.S. = Archivo de la Embajada Española ante la Santa Sede; A.G.S. = Archivo General de Simancas; A.S.V. = Archivo Secreto Vaticano; B.N. = Biblioteca Nacional; Col. Sal $=$ Colección Salazar y Castro; Inst. Misc. $=$ "Instrumenta Miscellanea"; OO. MM. = Órdenes Militares; R.A.H. = Real Academia de la Historia; Reg. Aven. - "Registra Avenionensia"; Reg. Lat. = "Registra Lateranensia"; Reg. Vat. - "Registra Vaticana"; Reg. Suppl. = "Registra Supplicationum".

$" i$ Está reconociendo Inocencio III al maestre y hermanos del Pereiro el derecho a la prescripción adquisitiva o usucapión ? Ésta consistía en la adquisición de la propiedad o de derechos por la posesión continuada durante el tiempo y con los requisitos exigidos por la ley, en este caso más de cuarenta años. Sin embargo, la bula no dice expresamente que se trate de una prescripción. 
ciones y adiciones, defectos muy comunes en la formación de cadenas de transmisión oral.

\section{LA ORDEN DEL PEREIRO-ALCÁNTARA Y LA JURISDICCIÓN PAPAL.}

La opinión tradicional era que la orden de San Julián del Pereiro quedó libre de la jurisdicción episcopal y sometida directamente al Papado con la bula del 4 de abril de 1183, otorgada por Lucio III a favor del maestre Gómez y de los freires de la orden ${ }^{78}$. Sin embargo, pueden plantearse objeciones a esta afirmación.

Rades y Andrada, al referirse a la bula de Lucio III, mantiene la postura tradicional: "Hizo exenta a esta orden, y que fuese nullius diocesis, a suplicación del dicho maestre, y de los prelados..." ${ }^{79}$. El otro cronista de la orden, frey Alonso de Torres y Tapia, reconoce que el documento pontificio del papa $\mathrm{Lu}$ cio expresaba sin ambigüedades que la orden quedaba sometida directamente al romano pontífice. Pero, se muestra dubitativo con respecto a la posibilidad de que la orden gozase ya de este privilegio desde tiempos anteriores: "Por la bula que poco ha pusimos de la santidad de Alejandro III no lo quedaba (inmediata a la Sede Apostólica) la del Perero, a lo menos no se ven en ella las palabras que pide el derecho, aunque por otros títulos no falta razón para entender lo contrario"so.

Si analizamos la primera bula conservada, dirigida a la orden el 29 de diciembre de 1176 por el pontífice Alejandro $\mathrm{III}^{81}$, podemos concluir que aparentemente, salvo quizá las palabras "sub Beati Petri et nostra protectione suscipimus", no hay ninguna referencia a que la orden del Pereiro dependiera de forma inmediata del papa. La frase referida de que la casa del Pereiro queda bajo la protección de San Pedro y del papa no es lo suficientemente explícita y clara como para expresar un exención jurisdiccional tan importante. Además, la parte final de la bula alejandrina decreta que nadie se atreva a molestar a la casa de San Julián, ni sus posesiones y que sus bienes se mantengan íntegros,

${ }_{78}$ B) A.C.C., leg. 276, $n^{\circ} 18$; C) B.N., ms. 621, f. 13, ff. 134-41, ff. 141-49; D) R.A.H., Col. Sal., I-19, ff. 180-82; I-37, ff. 184-87; E) A.E.E.S.S., cod. 417, f. 231

${ }^{79} \mathrm{~F}$. de RADES Y ANDRADA, Op. cit., f. $2 \mathrm{v}$.

80 A. de TORRES Y TAPIA, Op. cil., f. 85 .

81 B) B.N., ms. 622, f. 6; C) R.A.H., Col. Sal., I-19, ff. 180-82; D) A.H.N., OO. MM., Reg. Escrituras Calatrava, t. I, f. 58. Algunos autores fechan incorrectamente esta bula al afirmar que es de 1177. El origen de la equivocación es haber seguido el cómputo florentino del estilo de la Encarnación. La fecha correcta es 1176 . Al resolver la fórmula cronológica debemos seguir el cómputo pisano, que es el que parece haber utilizado en esta bula la Cancillería Pontificia de Alejandro III, aunque tal cómputo no era habitual en dicho pontificado. 
dejando a salvo la autoridad de la Sede Apostólica y la "justicia canónica" de los diocesanos ${ }^{82}$. Por tanto, San Julián del Pereiro quedaba sometido también a la autoridad de los obispos diocesanos.

Si proseguimos con nuestro análisis, esta vez sobre la bula de Lucio III, podemos comprobar que las cosas cambian sustancialmente. El preámbulo de este documento incluye una aseveración que parece contradecir la opinión tradicional: la orden del Pereiro no ha estado, hasta ese momento, sujeta a ningún obispo por ley diocesana ${ }^{83}$. En la parte dispositiva Lucio III decretaba que, a excepción del romano pontífice, nadie ose promulgar sentencias de entredicho, excomunión o suspensión en aquel lugar y contra los hermanos del Pereiro $^{84}$. Más adelante, al referirse a las ordenaciones de clérigos, al crisma, al óleo santo y a las consagraciones de los altares, Lucio III da su autorización para que puedan recibirlos de cualquier obispo católico $0^{85}$. En la parte final de la bula el papa dejaba a salvo sólo su autoridad ${ }^{86}$. Por lo tanto, el papa Lucio dejaba sometida directamente bajo su juriśdicción y libre del control diocesano a la orden de San Julián del Pereiro. Como compensación por la libertad así acordada, el pontífice Lucio III estableció el pago anual a la Santa Sede de un maravedi ${ }^{87}$.

A la vista de estos datos ¿por qué en el preámbulo de la bula de Lucio III se afirma que la orden hasta ese momento no había estado sujeta a ningún pontífice por ley diocesana, cuando seis años antes Alejandro III había dejado a salvo "la justicia canónica de los diocesanos"? No podemos responder con certeza a esta cuestión. Cabe la posibilidad, creemos que remota, de que haya existido otro documento pontificio - hoy extraviado - que sometiera a los sanjulianistas directamente al Papado y los dejara libres de la jurisdicción de los diocesanos, promulgado tras la bula de diciembre de 1176 y antes de la bula de 1183. O bien que esta cuestión no quedara suficientemente clara y fuera de discusión con el documento del papa Alejandro, siendo precisa la

82 "Decernimus ergo, ut nutli omnino hominum liceat prefatam Domum S. Iuliani temere perturbare, aut eius possessiones auferre, vel ablata retinere, minuere, seu quibuslibet vexationibus fatigare; sed illibata omnia, et integra conserventur, eonum pro quorum gubernatione, et sustentationes concessa sunt usibus omnimodis pro futura, salva Sedis Apostolice auctoritate et diocesanorum canonica iustitia".

83 "Nulli pontifici hactenus fuerit diocesana lege subiectus".

84 "Statuentes, ut preter romanum pontificem, nullus locum ipsum interdicto supponat, vel in fratres in eo commorantes excommunicationis, vel suspensionis sententiam ferre presumat".

Bs "Chrisma vero, oleum sanctum, consecrationes altarium seu basilicarum, ordinationes clericorum seu monachorum, qui ad sacros ordines fuerint promovendi, a quocumque malueritis catholico suscipiatis episcopo".

86 "(...) salva Apostolice Sedis auctoritate".

87 "Ad indicium autem percepte huius a Romana Ecclesia libertatis marapetinum unum singulis annis nobis, nostrisque successoribus persolvetis". 
intervención de Lucio III para evitar posibles interferencias y conflictos de los obispos diocesanos con la orden. $O$ quizá que la cofradía del Pereiro hubiese liegado a una exención de hecho que después fue confirmada, de derecho, por Lucio III en 1183.

En cualquier caso podemos afirmar que el papa Lucio III estableció, sin posibilidad de duda, la exención de la orden o cofradía del Pereiro con respecto a los obispos y su dependencia directa del romano pontífice. Este privilegio será defendido con mucho celo por los sanjulianistas o alcantarinos, ya que los obispos diocesanos tenderán a considerar la orden, sus posesiones y sus miembros, sometidos a su autoridad. Éste será el origen de numerosas e interminables controversias entre obispos y freires militares que, en algunas ocasiones, los papas no resolverán -probablemente por la presión ejercida por los poderes diocesanos - con la oportuna diligencia y claridad. Es muy significativo el caso de Gregorio IX (1227-41): en una bula confirmatoria de privilegios, exenciones y libertades del 16 de junio de $1235^{88}$, prohíbe importunar a la orden de San Julián del Pereiro dejando a salvo la autoridad de la Sede Apostólica y la diocesana ${ }^{89}$, con lo cual enmendaba las disposiciones de Lucio III. Esta decisión contrasta con otro documento pontificio del mismo Gregorio IX tres años más tarde (16 de marzo de 1238) ${ }^{90}$, probablemente causado por las airadas reclamaciones de los freires del Pereiro-Alcántara molestos por las sentencias de excomunión y entredicho lanzadas contra sus iglesias. En él ordenaba a los prelados leoneses que respetaran a los freires, pues estaban libres de la jurisdicción diocesana y sometidos directamente a la Sede Apostólica ${ }^{91}$.

En definitiva: los documentos pontificios nos muestran cómo en la práctica era difícil mediar entre los freires y los obispos diocesanos, precisar el límite de las respectivas esferas de competencia y concordar una jurisdicción con la otra. Aunque la bula de 1183 eximía a los sanjulianistas de la jurisdicción episcopal y los hacía inmediatos a la Santa Sede, los freires se vieron obligados una y otra vez a solicitar amparo al romano pontífice para que confirmara que solamente él, y no los obispos diocesanos, mantenía una jurisdicción superior sobre la orden. Los poderes diocesanos no aceptaron de buen grado que los alcantarinos no estuviesen sometidos a su autoridad; por esto durante toda

${ }^{88}$ B) A.S.V., Archivum Arcis, Arm. I-XVIII, $\mathrm{n}^{\circ}$ 1682, ff, 1r-4v. Mansilla duda de que la bula sea de Gregorio IX; vid. D. MANSILLA, La documentación espantola del Archivo del Castel S. Angelo (395-1498), Roma 1959, ñ.63.

89 "salva eiusdem Sedis Apostolice auctoritate et in predictis eclesiis diocesanorum episcoporum canonica iustitia".

90 B) A.S.V., Reg. Aven, 238, f. 543r-v; C) A.S.V., Reg. Vat. 295, f. $136 r-v$.

9! "Cum dilecti filii fratres Domus de Pirario Alcantarensis, Cisterciensis ordinis, nullum habeant episcopurn, vel prelatum, preter romanum pontificem...". 
la Edad Media intentaron, incluso mediante presiones ante la Sede Apostólica, menoscabar la libertad jurisdiccional que concedía el Papado a los freires.

El romano pontífice, ya desde las primeras bulas concedidas a la orden de San Julián del Pereiro, mostró su celo por proteger las personas y bienes de la orden. Aquél era, muchas veces, fruto de la insistente petición de protección por parte de los freires sanjulianistas. Alejandro III en su bula del 29 de diciembre de 1176 recibió bajo su tutela al prior y hermanos de San Julián ${ }^{92}$. Asimismo puso bajo su protección los bienes de la orden ${ }^{93}$. Lucio III en la bula de 1183 volvió a reiterar, con los mismos términos, la protección de la Sede Apostólica sobre las personas y bienes de San Julián.

Inocencio III (1198-1216) y Honorio III (1216-27) confirmaron de forma general esta protección pontificia sobre la orden del Pereiro-Alcántara. Pero fue, sobre todo, Gregorio IX (1227-41) el papa que más destacó por proteger los bienes de esta orden militar, tanto bajo el maestrazgo de Arias Pérez (122734) como bajo el de Pedro Yáñez (1234-54). Muy especialmente con este último, como afirma Torres y Tapia ${ }^{94}$. Cuando subió el papa Gregorio al solio pontificio (marzo de 1227) la orden del Pereiro-Alcántara ya estaba bastante extendida por el reino de León y ello ocasionó pleitos, disputas y conflictos con personas eclesiásticas y seglares, que discutían la pacífica posesión de los bienes de los freires. Éstos consiguieron, mediante las gestiones oportunas de sus procuradores en Roma, que el papa dirigiera una temprana bula (31 de mayo de 1227$)^{95}$ a todos los prelados de la Iglesia en el reino leonés para proteger las casas, posesiones u otros bienes -de su propiedad, de la de sus vasallos o donados a la orden por legítimo testamento o última voluntad- invadidos o retenidos injustamente.

La mayoria de las siguientes bulas gregorianas fueron concedidas a instancias de los procuradores de la orden en Roma, que solicitaron a la Sede Apostólica la protección de sus iglesias, villas, castillos, haciendas, posesiones, bienes y lugares que los reyes, príncipes y fieles habían donado a los alcantarinos $^{96}$. Gracias a las bulas, dichas donaciones adquirían una mayor firmeza. Así, por ejemplo, Gregorio IX en octubre de 1232 confirmó a la orden de Al-

\footnotetext{
92 En esta bula se denomina a Gómez prior, y no maestre: "Alexander episcopus.., dilectis filiis Gometio, priori S. Iuliani de Pirario, eiusque fratribus". En este caso "prior" tiene la acepción de superior general de la orden, no de cabeza jerárquica de los clérigos de dicha institución.

93 "statuentes, ut quascumque possessiones, quecumque bona eadem Domus S. Iuliani in presentiarum iuste et canonice possidet, aut in futurum concessione pontificum, largitione regum, vel principum, oblationes fidelium, seu aliis iustis modis, prestante Domino, poterit adipisci, firma vobis vestrisque successoribus, et ilibata permaneant".

94 A. de TORRES Y TAPIA, Op. cit., I, f. 287.

95 B) R.A.H., Col. Sal., I-19, ff. 202-203.

96 Por ejemplo la bula del 5 de noviembre de 1229: B) B.N., ms. 622, ff. 212-15.
} 
cántara el Pereiro y otros bienes ${ }^{97}$. Un año después el papa dirigió su epístola apostólica al obispo de Coria, para que las posesiones de los freires alcantarinos que estuvieran ilícitamente en manos de eclesiásticos o seglares volviesen a sus legítimos poseedores ${ }^{98}$. Igual recomendación hizo el sucesor de Pedro el 18 de marzo de 1337 al deán, maestrescuela y tesorero de Ciudad Rodrigo: que fuesen respetadas las posesiones de la orden en Zamora ${ }^{99}$. La orden de Alcántara pidió protección papal sobre algunos bienes en litigio con el arzobispado de Toledo ${ }^{100}$, con la orden del Temple ${ }^{101}$, con el concejo de Talavera ${ }^{102}$, etc. El pontífice, durante el mes de marzo de 1238 , también dio su protección a los bienes de familiares de la orden y de otros fieles cristianos que habían dejado a Ios alcantarinos por última voluntad en Zamora ${ }^{103}$, Coria ${ }^{104}$, Salamanca ${ }^{105}$ y Ciudad Rodrigo ${ }^{106}$.

El maestre y hermanos de Alcántara acudieron al papa como a su inmediato superior jerárquico para garantizar y defender sus bienes y personas. Una protección no sólo limitada a los primeros tiempos, sino prolongada a lo largo de toda la Edad Media. Por ejemplo, Alejandro IV el 12 de febrero de 1259 ordenó al deán y tesorero de Zamora proteger los bienes del monasterio del Pereiro-Alcántara en los reinos de Castilla, León y Portugal ${ }^{107}$. Benedicto XIII el 23 de noviembre de 1409 mandó a los obispos de Palencia y Plasencia, entre otros, averiguar qué bienes habían sido ilegalmente enajenados a la orden para que fuese gestionada su restitución ${ }^{108}$. Sixto IV el 13 de noviembre de 1480 confirmó que la fortaleza de Burguillos debía permanecer dentro del vasallaje de la orden de Alcántara ${ }^{109}$. Inocencio VIII, en enero de 1487, expidió dos bulas. La primera para condenar, mediante las oportunas censuras eclesiásticas, a los que habían enajenado ilegalmente bienes de la mesa maestral de

97 B) R.A.H., Col. Sal., J-19, ff. 210-11.

98 Edita: I. J, de ORTEGA Y COTES, Bullarium, 38-39.

99 B) B.N., ms. 622, ff. 194-97. No sabemos exactamente si se refiere a las posesiones de Zamora o Coria, ya que el copista tacha Zamora y escribe encima Coria. No se puede contrastar con otra versión, porque sólo conservamos esta copia.

100 Bula del 8 de mayo de 1337: A) A.H.N., Sellos, arm. $n^{\circ}$. 1, c. $5, \pi^{\circ} 27$.

101 Bula del 28 de marzo de 1235, ed.: I. J. de ORTEGA Y COTES, Bullarium, 51-53. Esta bula está inserta en un documento del 31 de marzo de 1243 sobre el conflicto referente a la villa de Ronda entre la orden de Alcántara y el Temple.

${ }_{102}$ Bula del 26 de enero de 1238, ed.: I. J. de ORTEGA Y COTES, Bullarium, 45-46.

1013 B) R.A.H., Col. Sal., I-19, f. 217.

104 B) B.N., ms. 622, ff. 204-207; C) R.A.H., Col. Sal, I-19, f. 217 r-v.

19s Ed.: I. J. de ORTEGA Y COTES, Bullarium, 48.

106 Ed.: I. J. de ORTEGA Y COTES, Bullarium, 48-49.

${ }^{107}$ B) B.N., ms. 621, f. 24.

${ }_{108}$ B) A.S.V., Reg. Aven. 335, f. 214r-v,

${ }^{109}$ B) A.G.S., Reg. Gral. Sello, 1480-XI, ff. 36 y 46.

Medievalia Hispanica

Hispania Sacra 49 (1997) 
Alcántara ${ }^{10}$. La segunda para dictar sentencias de excomunión a todos aquellos que atentasen contra los bienes de los alcantarinos ${ }^{111}$.

El maestre de Alcántara ostentaba la potestad suprema sobre la orden, sin embargo - debido a su condición seglar-, delegaba el poder espiritual en el prior, que era un freire ordenado. El maestre y la orden, como hemos expuesto, estaban sujetos de forma inmediata al Papado. Por tanto, correspondía al romano pontífice confirmar la elección del maestre. Los freires representantes de la orden elegían a su maestre conforme a las normas canónicas de elección. Las primeras bulas conservadas, de Alejandro III y Lucio III, ya prohibían la elección maestral de forma subrepticia o irregular. Existen algunas bulas de confirmación de la dignidad maestral, pero no sabemos si la Santa Sede concedió siempre este tipo de bulas tras la elección del maestre, o bien sólo en algunos casos con el fin de conceder mayor firmeza y seguridad a la elección. Conservamos las bulas de confirmación de los maestres Fernando Rodríguez de Villalobos (1394-1408) ${ }^{112}$, Gutierre de Sotomayor (1432-55) ${ }^{113}$, Gómez de Cáceres y Solís (1458-70/72) ${ }^{114}$ y del infante don Sancho (1308-16) ${ }^{115}$. También existe una bula muy peculiar de nombramiento directo de Juan de Zúñiga (1475-94) como maestre y de su padre Álvaro de Zúñiga como administrador de la orden, debido a la minoría de edad de aquél. Se trata de una decisión papal sin precedentes, que sólo es explicable teniendo en cuenta los turbulentos incidentes producidos en la orden de Alcántara durante la segunda mitad del siglo XV. Estos enfrentamientos tuvieron como principal protagonista al clavero y maestre de la orden, Alonso de Monroy, enemistado con el maestre Gómez de Cáceres y Solís y después con la familia Zúñiga ${ }^{116}$. Por parte pontificia el litigio se zanjó con la censura de Alonso de Monroy, privado del reconocimiento como maestre por la Sede Apostólica ${ }^{117}$.

El papa siempre defendió el maestrazgo frente a cualquier tentación hegemónica de los comendadores. Las bulas pontificias documentan bien el contencioso entre los Zúñiga y el comendador Diego de Santilllán, hermano del obispo de Osma, Francisco de Santillán, con el que casi siempre actuó con-

\footnotetext{
110 Ed.: I. J. de ORTEGA Y COTES, Bullarium, 245.

11 I Ed.: I. J. de ORTEGA Y COTES, Bullarium, 245-46.

112 Bula del 27 de abril de 1396: B) A.S.V., Reg. Aven, 300, ff, 244v-245r.

113 Bula del 7 de diciembre de 1432: B) A.S.V., Reg. Vat. 370, ff. $118 \mathrm{v}-119 \mathrm{r}$.

I:4 Bula del 25 de octubre de 1458, ed.: I. J. de ORTEGA Y COTES, Bullarium, 220-22.

115 Bula del 5 febrero de 1410: B) A.S.V., Reg. Aven. 335, ff. 203v-204r.

116 F. de RADES Y ANDRADA, Op. cit., cptos. 35-37.

II7 Bula del 20 de diciembre de 1477; B) A.S.V., Reg. Vat. 668, ff. 42r-47v.
} 
juntamente ante la Sede Apostólica ${ }^{118}$. El papa Sixto IV concedió primero a Diego de Santillán la encomienda mayor de la orden ${ }^{119}$ y unos meses después la de Portezuelo ${ }^{120}$. Con el enorme poder acumulado, Diego de Santillán se enfrentó a Álvaro de Zúñiga —administrador del maestrazgo- y a su hijo Juan de Zúñiga -maestre-. Sixto IV defendió con todo vigor la autoridad maestral y anuló las exenciones concedidas a Diego de Santillán, al que obligó a obedecer a los Zúñiga ${ }^{121}$. El conflicto se alargó y aparecieron nuevos litigios entre los Zúñiga y Diego de Santillán ${ }^{122}$, por lo que otro papa, Inocencio VIII, se vio en la necesidad de confirmar la bula de su antecesor, Sixto IV, en la que ordenaba el sometimiento de Diego de Santillán al maestre ${ }^{123}$.

La orden de Alcántara, durante el Cisma de Occidente, siguió la obediencia de los papas de Aviñón, con los que mantuvo -como vamos a exponer- una estrecha relación. No hemos encontrado en la Sala de Índices y Catálogos del Archivo Vaticano, en cambio, ningún documento dirigido a los alcantarinos por los pontífices de las obediencias romana o pisana. La monarquía castellana presto su obediencia al bando clementista en 1381, aunque el acta formal de adhesión y fidelidad, a la que se sumó Martín Yáñez de la Barbuda —maestre de la orden de Alcántara - está datada en Huertos de Simales el 16 de agosto de $1391^{124}$.

Poseemos, hasta estos momentos, diez documentos pontificios dirigidos a la orden por Clemente VII de Aviñón (1378-94) y siete por Benedicto XIII (1394-1417). Estos pontífices pugnaron con los papas de las obediencias romana y pisana por ganarse la voluntad de la mayoría de los personajes eclesiásticos y civiles de los reinos españoles, para evitar la temida sustracción de obediencia. Llama la atención, por ejemplo, una bula del 21 de septiembre de 1384 dirigida por Clemente VII a los arzobispos de Toledo y Sevilla y al obispo de Burgos ${ }^{125}$. En ella notifica la concesión al rey Juan I de Castilla de nombrar maestres de las órdenes de Santiago, Calatrava y Alcántara si quedaran vacantes dichas dignidades durante su reinado. Esta medida iniciaba un proceso de incorporación de los maestrazgos de las Órdenes Militares a la Corona que iba a culminar con los Reyes Católicos. Los papas de Aviñón no dudaron

\footnotetext{
118 Bula del 27 de octubre de 1475: B) A.S.V., Reg. Vat. 664, ff. 187v-188r.

It9 Bula del 16 de abril de 1474: B) A.S.V., Reg. Vat. 562, ff. 103v-105r.

120 Bula del 14 de septiembre de 1474, ed.: I. J. de ORTEGA Y COTES, Bullarium, 224-227.

121 Bula del 19 de septiembre de 1480: B) Ed.: I. J. de ORTEGA Y COTES, Bullarium, 235-37.

122 Bula del 24 de enero de 1483; B) A.S.V., Reg. Vat. 676, ff. 289r-290r.

123 Bula del 10 de enero de 1487, cita: A. de TORRES Y TAPIA, Op. cit., II, f. 525.

124 A) A.S.V., Inst. Misc. $n^{\circ} .3499$.

125 B) A.S.V., Reg. Aven. 238, f. 543r-v; C) A.S.V., Reg. Vat. 295, f. 136r-v,
} 
en mostrarse muy generosos con sus súbditos, creando así la ocasión propicia para los abusos. Si el comienzo de todo pontificado provocaba la afluencia de multitud de súplicas a la Sede Apostólica, el año $1378^{126}$, por ejemplo, marcó un hito, ya que Clemente VII necesitaba imperiosamente adictos a su obediencia. Los alcantarinos también aprovecharon esta favorable coyuntura para obtener numerosos beneficios de Clemente y Benedicto, como lo demuestran las diecisiete bulas encontradas hasta el momento presente.

Conservamos un rótulo de súplicas ${ }^{127}$, de gran interés, dirigido por la orden de Alcántara al nuevo papa elegido en el Concilio de Constanza: Martín V. Santiago y Alcántara fueron las únicas órdenes militares españolas representadas en dicho concilio ${ }^{28}$. Gracias al mencionado rótulo sabemos que la orden mandó dos embajadores al Concilio de Constanza, Pedro González y Gonzalo Álvarez, aunque este último hubo de retornar a España por enfermedad antes de llegar a Constanza. Por tanto, fue sólo Pedro González el que presentó al papa las aspiraciones de los alcantarinos: confirmación de todos los privilegios de la orden, especialmente dos de Inocencio $V$ relativos a la elección de maestre y a la adquisición y retención de bienes inmuebles; y despacho de unas letras conservatorias perpetuas a favor del propio maestre y de cada caballero de la orden. Martín V aprobó la súplica, pero con algunas restricciones: las letras conservatorias debían expirar a los diez años. Cinco días después, otorgó a Juan de Sotomayor, maestre de la orden, indulgencia plenaria "in articulo mortis"129. En enero del siguiente año Martín V también se mostró muy favorable: confirmó todas las bulas, concesiones e inmunidades que habían sido recibidas por los alcantarinos en tiempos anteriores ${ }^{130}$.

También, aunque un poco más tarde ${ }^{131}$, el papa dio su autorización a la orden de Alcántara para poder recuperar las villas, fortalezas y demás bienes en tierras portuguesas. Éstas les habían sido enajenadas porque el reino portugués siguió la obediencia de los papas romanos.

Posiblemente en tiempos de Honorio III (1216-27) la orden de Alcántara mantenía ya procuradores estables - compartidos quizá con otras Órdenes

${ }^{126} \mathrm{~K}$. HANQUET; U. BERLIÈRE (eds.), Documents relatifs au Grand Schisme II. Lettres de Clément Vll (1378-79, Roma-Bruxelles-Paris 1930, p. XXXIV.

${ }^{127}$ Súplicas del 14 de diciembre de 1417: B) A.S.V., Reg. Suppl. 106, ff. 294v-295v.

128 J. GOÑ GAZTAMBIDE, "Los espafioles en el Concilio de Constanza" Hispania Sacra XVIII (1965), p. 278

129 B) A.S.V., Reg. Suppl. 106, f. 179v.

130 Ed.: I. J. de ORTEGA Y COTES, Bullarium, 191.

131 Cit.: A. de TORRES Y TAPIA, Op. cit., II, f. 308. 
Militares- ante la Sede Apostólica con diversas funciones. Éstas eran presentar las súplicas ${ }^{132}$ correspondientes al papa, agilizar las gestiones, y, en general, tratar de los diversos asuntos bilaterales entre la orden y la Curia Romana. Aún así, la existencia de estos representantes de la orden -permanentes ${ }^{133}$ y expertos en el oficio- no eliminaron la necesidad de mandar emisarios ante el papa con motivo de ocasiones especiales. Hasta ahora las bulas encontradas no nos aportan más datos sobre este tema. Sí suministra alguna información la crónica de Torres y Tapia ${ }^{134}$. Este cronista cita por primera vez en 1225 (por error fecha la bula en 1221) a procuradores de la orden de Alcántara que se presentaron ante el papa, para que éste les reconociera como hijos suyos y solicitar la confirmación de las gracias y favores que los pontífices romanos habían otorgado a la orden ${ }^{135}$. Torres y Tapia cita continuamente a los procuradores de la orden al tramitar las bulas de Gregorio $\mathrm{IX}^{136}$. Sin embargo no sabemos en qué se fundamenta este cronista para citar procuradores de la orden en fecha tan temprana. Tampoco especifica si estos procuradores eran exclusivamente de la orden de Alcántara o bien comunes con otras órdenes militares. Sabemos que en 1188 las órdenes de Santiago, San Juan y el Temple prometieron que sus procuradores trabajarían para las tres órdenes en la Curia Romana y que Santiago y Calatrava hicieron un compromiso parecido en $1243^{137}$. Es posible, aunque por el momento es una hipótesis no documentada, que los alcantarinos -con menor potencia económica que los santiaguistas o calatravos- llegasen a un acuerdo similar con otra orden militar o poder eclesiástico. Mantener procuradores permanentes en la curia era muy costoso, por lo que era habitual que varias instituciones compartieran estos representantes.

Tras estudiar la documentación pontificia referida a los alcantarinos, es necesario destacar la figura de un purpurado cisterciense de la curia en la época del papa Alejandro IV (1254-61): Juan de Toledo, cardenal presbítero de San Lorenzo "in Lucina", un eclesiástico de origen inglés que había desempeñado el cometido de traductor en Toledo. Había sido creado cardenal por Inocencio

132 Una de las funciones de los procuradores durante el siglo XIII era redactar las peticiones de la orden en la forma adecuada para que se pudiesen plasmar en una súplica. En el siglo XIV las súplicas adquirieron un carácter oficial y su texto debía ser compuesto "secundum stilum curiae". Vid. L. BOYLE, A survey of the Vatican Archives and of its Medieval holdings, Toronto 1972, pp. 149-50.

133 Sobre los comienzos de los procuradores permanentes hay un estudio antiguo de: $\mathbf{R}$. von HECKEL, "Das Aufkommen der stăndigen Prokuratoren an der păpstlichen Kurie im 13. Jahrhundert" Miscellanea Francesco Ehrle II (Studi e Testi 38, Rome 1924), pp. 311-43.

1.34 A. de TORRES Y TAPIA, Op. cit., I, f. 229.

135 Estas súplicas dieron origen a la bula del 24 de septiembre de 1232: B) R.A.H., Col. Sal., I-19, f. 209.

136 A. de TORRES Y TAPIA, Op. cit., I, ff. 239, 287, 291, passim.

137 D. LOMAX, La orden de Santiago (I170-1275), Madrid 1965, p. 22. 
IV en su primera promoción ${ }^{138}$. En seis bulas aparece como cardenal protector de la orden de Alcántara. La mayoría de las veces es citado como testigo de la sujeción de los alcantarinos al Císter -orden a la que pertenecía este cardenaldesde los comienzos ${ }^{139}$, como es en el caso de cuatro bulas ${ }^{140}$. En otro documento atestigua lo mismo, pero referido a las órdenes de Alcántara y Calatra$\mathrm{va}^{141}$. En la bula que falta por citar aparece como mediador en general ${ }^{142}$, sin hacer mención de la sujeción de la orden al Císter. Es un caso de mediación único, entre todas las bulas alcantarinas encontradas. Demuestra la especial amistad o cercanía de dicho miembro de la curia con los alcantarinos.

${ }^{138}$ C. EUBEL, Hierarchia Catholica Medii Aevi sivi Summorum Pontificum, S.R.E. Cardinalium, ecclesiarum antistitum series ab anno 1198 usque ad annum 1431 perducta, Monasterii 1913, t. I, p. 7.

139 "Cum autem prout dilectus filius noster loannes, tituli S. Laurentii in Lucina presbiter cardinalis exposuit coram nobis, in monasterio vestro, ab initio sue fundationis Cisterciensis Ordo institutus fuerit, et semper etiam observatus, vosque sub obedientia, et visitatione generalis Cisterciensis Capituli maneatis, nos intuitu ipsius cardenalis, vestris supplicationibus annuentes..." (bula del 1 de diciembre de 1258).

${ }_{140}$ Bula del 1 diciembre de 1258: B) R.A.H., Col. Sal., I-19, ff. 228-29. Bula del 9 de enero de 1259: B) B.N., ms. 622, ff. 38-41; C) R.A.H., Col. Sal., I-19, ff. 239-40. Bula del 18 de marzo de 1259: B) B.N., ms. 622, ff. 20-23; C) R.A.H., Col. Sal,, I-19, ff. 237-38. Bula del 29 de noviembre de 1259: B) B.N., ms. 622, f. 20; C) R.A.H., Col. Sal., I-19, ff. 241-42.

141 Bula del 12 de febrero de 1259: B) R.A.H., Col. Sal, I-19, f, 236.

142 Bula del 31 de enero de 1259: B) R.A.H., Col. Sal., I-19, f. 235. 